\title{
A Novel Mutation in FGF23 Causing Severe Manifestation of Hyperphosphataemic Familial Tumoral Calcinosis
}

\author{
Tania-Tofail ${ }^{1, *}$, Fariduddin $M^{1}$, Haq $T^{1}$, Selim $S^{1}$, Jahan $S^{1}$, Khan $M A^{1}$, Mustari $M^{1}$, Banu $H^{1}$, \\ Datta $\mathrm{NK}^{2}$, Islam MA ${ }^{2}$, Hossain $\mathrm{MS}^{3}$, Hasanat MA ${ }^{1}$ \\ ${ }^{1}$ Department of Endocrinology, BSMMU, Dhaka, Bangladesh \\ ${ }^{2}$ Department of Orthopaedics, BSMMU, Dhaka, Bangladesh \\ ${ }^{3}$ Department of Genetic Engineering, DU, Dhaka, Bangladesh \\ *Corresponding author: tania.ali194@gmail.com
}

\begin{abstract}
We present a 16-year girl, second issue of a consanguineous couple presented with painless symmetrical bony swellings around hips for 3 years. She lost $25 \mathrm{~kg}$ weight due to profound anorexia in the first year of illness and developed secondary amenorrhea. Last 7 months she had repeated generalized tonic clonic seizure due to hypocalcaemia. The bony swellings were located in both gluteal regions and were $30 \times 35 \mathrm{~cm}^{2}$, hard and non tender. Mobility of hip joints were restricted. Except for severe wasting as a part of generalized cachexia other systemic examination was unremarkable. Investigations revealed anaemia (Hb-E trait), low albumin, low corrected calcium (during convulsions) otherwise normal, persistently high phosphate \& vitamin-D level, normal iPTH \& alkaline phosphatase (ALP), low serum ascorbic acid, normal ESR \& CRP. X-ray \& CT scan of pelvis showed large calcified mass in periarticular soft tissues. Biopsy confirmed presence of dystrophic calcification. Diagnosis of tumoral calcinosis was based on biochemical parameters, imaging and biopsy findings. A homozygous novel mutation in FGF homology domain: B-21 mutated from G to A at 232 in exon 2. As a result glutamic acid is replaced by lysine. Phosphate restricted diet and phosphate lowering agent improved biochemical paramaters. Surgical excision has been withheld. Contemporary manifestation of hFTC and Hb E trait; two disease of autosomal recessive inheritance in an individual makes it extremely rare. High index of suspicion is needed for early diagnosis and treatment.
\end{abstract}

Keywords: Tumoral calcinosis, Hyperphosphataemia, FGF23

Cite This Article: Tania-Tofail, Fariduddin M, Haq T, Selim S, Jahan S, Khan MA, Mustari M, Banu H, Datta NK, Islam MA, Hossain MS, and Hasanat MA, "A Novel Mutation in FGF23 Causing Severe Manifestation of Hyperphosphataemic Familial Tumoral Calcinosis." American Journal of Medical Case Reports, vol. 6, no. 5 (2018): 99-102. doi: 10.12691/ajmcr-6-5-6.

\section{Background}

Tumoral calcinosis (also referred to as hyperphosphatemic familial tumoral calcinosis, OMIM 211900) is a rare autosomal recessive metabolic disorder characterized by the development of often severe ectopic calcifications in soft tissues. Calcific masses are typically found around major joints such as the hip, elbow, shoulder, and knee. [1,2] Biochemical abnormalities associated with tumoral calcinosis include hyperphosphatemia secondary to increased renal tubular phosphate reabsorption and elevated or inappropriately normal 1,25-dihydroxyvitamin D [1,25(OH)2D] levels. [3] Furthermore, this disorder is occasionally associated with diaphysitis, hyperostosis, arterial aneurysms, dental abnormalities, and angioid streaks of the retina. The disease can be caused by inactivating mutations in either the fibroblast growth factor 23 (FGF23) gene, the UDP-N-acetyl-D-galactosamine:polypeptide $\mathrm{N}$-acetylgalactosaminyltransferase 3 (GALNT3) gene or in human KLOTHO (KL) gene. [4] Herein we report a patient with severe soft-tissue calcifications as well as multiple abnormalities of mineral homeostasis due to a point mutation in the FGF23 gene. To our knowledge, this mutation has not been reported earlier. Treatment with the phosphate binder sevelamer and the vitamin $\mathrm{C}$ successfully reduced the serum phosphate levels and led to a reduction of the calcified mass. This medical management has not been described previously.

\section{Case Presentation}

A 16-year-old girl, $2^{\text {nd }}$ issue of a consanguineous couple presented with gradually progressive bilateral hip swellings along with profound weight loss for last 3 years and recurrent convulsions for 1 year. She was in her usual state of health until she was 14-year-old. Her illness started with an episode of diarrhoea, abdominal pain and vomiting which resolved after conservative management. But it was followed by profound anorexia leading to 
continued weight loss amounting approximately $25 \mathrm{~kg}$ over last 3 years. It was not associated with fever, alteration of bowel habit or features of malabsorption. She developed secondary amenorrhoea as a consequence of her chronic illness. Since then she noticed swelling over her both hips which were insidious in onset, gradually increasing in size, painless, with no overlying skin change or discharge. Swellings have increased to such an extent that movement of hip has become difficult in each of the axes and patient has become bed bound. At this point, she was treated in a referral center \& coeliac disease and anorexia nervosa was excluded as differentials of her presentation. See Table 1. Her biochemical features revealed persistent hyperphosphataemia while other parameters i.e. corrected calcium, creatinine were normal. She was then started on phosphate restricting diet and sevelamer. See Table 2. These interventions improved her biochemical parameters but swellings continued to expand. In the interim, patient suffered several episodes of convulsions over the last 1 year amongst which she suffered from one episode of status epilepticus. Investigations revealed hypocalcaemia as the cause. Following normalisation of calcium she is now seizure free for last 1 year. Her birth history and perinatal period was unremarkable. She attained her milestones of development in due course. There is no history of such illness in her family.

On examination, patient was cachectic, bed bound, moderately anaemic, malnourished with a BMI of $1304 \mathrm{~kg} / \mathrm{m}^{2}$, vitals within normal limit. Musculoskeletal system examination revealed there are two masses in the lateral aspects of both hips extending up to anterior aspects, measuring about $30 \times 35 \mathrm{~cm}^{2}$, firm to hard in consistency, non-tender, irregular surface with restricted mobility of hip joints in extension and external rotation without any sign of inflammation. Systemic examination findings were within normal limit.

\section{Investigation}

See Table 1 \& Table 2 and Figures.

Table 1. Investigations done and their results. (at presentation)

\begin{tabular}{|l|l|}
\hline Test & Result/Finding \\
\hline CBC & Hb- $9.8 \mathrm{gm} / \mathrm{dl}$ \\
\hline S. albumin & $28 \mathrm{gm} / \mathrm{dl}(35-45 \mathrm{~g} / \mathrm{dl})$ \\
\hline S. creatinine & $0.6 \mathrm{mg} / \mathrm{dl}$ \\
\hline eGFR & $138.4 \mathrm{ml} / \mathrm{min} / 1.73 \mathrm{~m}^{2}$ \\
\hline LDH & $400 \mathrm{U} / \mathrm{L}$ \\
\hline Rheumatoid factor (RA) & negative \\
\hline Anti-nuclear antibody (ANA) & negative \\
\hline Anti-ds-DNA & negative \\
\hline p-ANCA* & negative \\
\hline c-ANCA & negative \\
\hline Bone marrow study & Non conclusive \\
\hline Upper GI endoscopy with biopsy & Non specific duodenitis \\
\hline Anti-TTG & negative \\
\hline CT scan of abdomen & normal \\
\hline USG of abdomen & normal \\
\hline MTB culture & No growth \\
\hline Fungal culture & No growth \\
\hline AFP & normal \\
\hline CA-19-9 & normal \\
\hline Hb electrophoresis & Hb-E trait \\
\hline & \\
\hline
\end{tabular}

Table 2. Biochemical parameters during follow up

\begin{tabular}{|l|l|l|l|}
\hline Parameter & $\begin{array}{l}\text { Patients value } \\
\text { At presentation }\end{array}$ & $\begin{array}{l}\text { Patients value } \\
\text { Following treatment }\end{array}$ & Normal Range \\
\hline $\begin{array}{l}\text { S. corrected calcium(mg/dl) } \\
\text { (except during convulsion) }\end{array}$ & 8.9 & 9.1 & $8.5-10.5$ \\
\hline Inorganic Phosphate (mg/dl) & 7.5 & 6.7 & $2.3-4.7$ \\
\hline Calcium-phosphate product & & & \\
\hline ALP(U/L) & 1264 & 125 & Up to 110 \\
\hline iPTH (pg/ml) & 44.6 & 27 & Up to 65 \\
\hline 25-OH vitamin D (pg/ml) & 80 & 41 & $31-50$ \\
\hline Urine Calcium (mg/dl) & 11 & & \\
\hline Urine phosphorus (mg/dl) & 407 & & \\
\hline BMD by DEXA & $\begin{array}{l}\text { T score -4.3 } \\
\text { Z score -5.3 }\end{array}$ & & \\
\hline CT scan of Brain & Calcification in both thalamo-ganglionic region & & \\
\hline EEG & normal & & $0.6-2$ \\
\hline S. Ascorbic acid (mg/dl) & $<.01$ & & \\
\hline
\end{tabular}

ALP- alkaline phosphatase, $\mathrm{iPTH}=$ intact parathyroid hormone, $\mathrm{BMD}=$ bone mass density, $\mathrm{DEXA}=$ dual energy $\mathrm{X}$-ray absorpsiometry, $\mathrm{EEG}=$ electroencephalogram.

\section{Biopsy Findings}

\subsection{Biopsy}

Histopathology from the masses revealed deposition of calcium hydroxyapatite. 


\subsection{Genetic Analysis}

EDTA blood samples were collected as per protocol. The following genes were sequenced: FGF23, alpha-KLOTHO \& GALNT3. Only exons were sequenced. A homozygous novel mutation was found in FGF homology domain. In exon 2: B-21 mutated from $\mathrm{G}$ to $\mathrm{A}$ at 232. As a result glutamic acid is replaced by lysine.

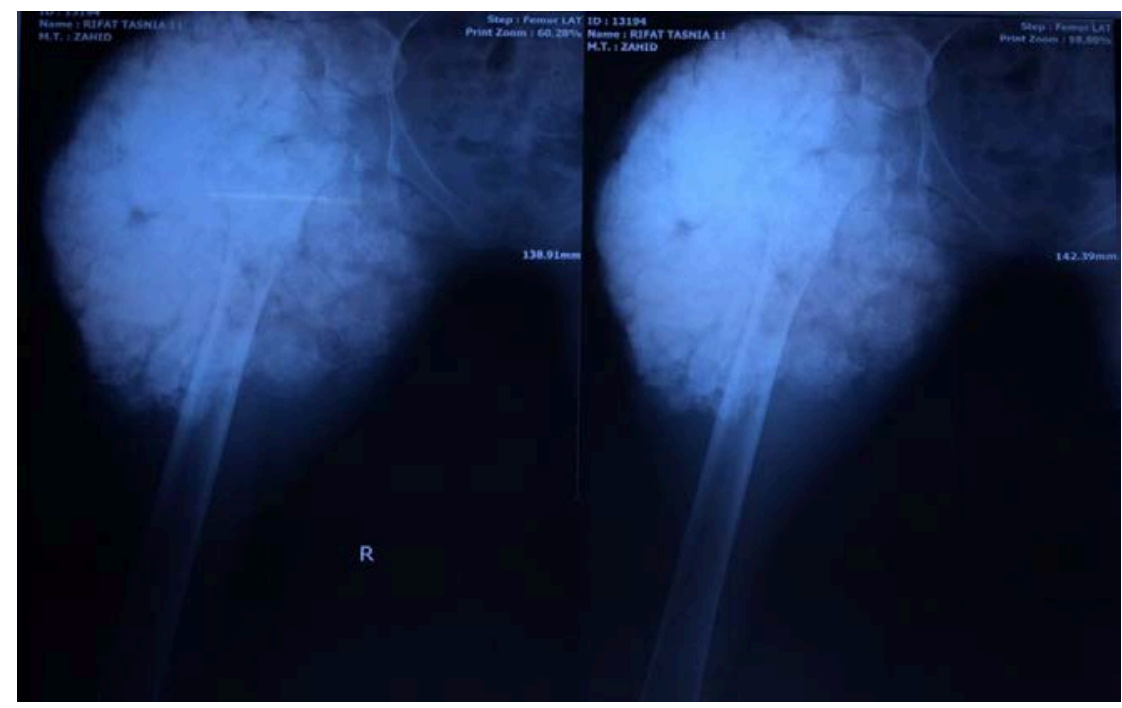

Figure A. X-ray of Hip joints.

Large calcified mass in periarticular soft tissues suggestive of tumoral calcinosis.

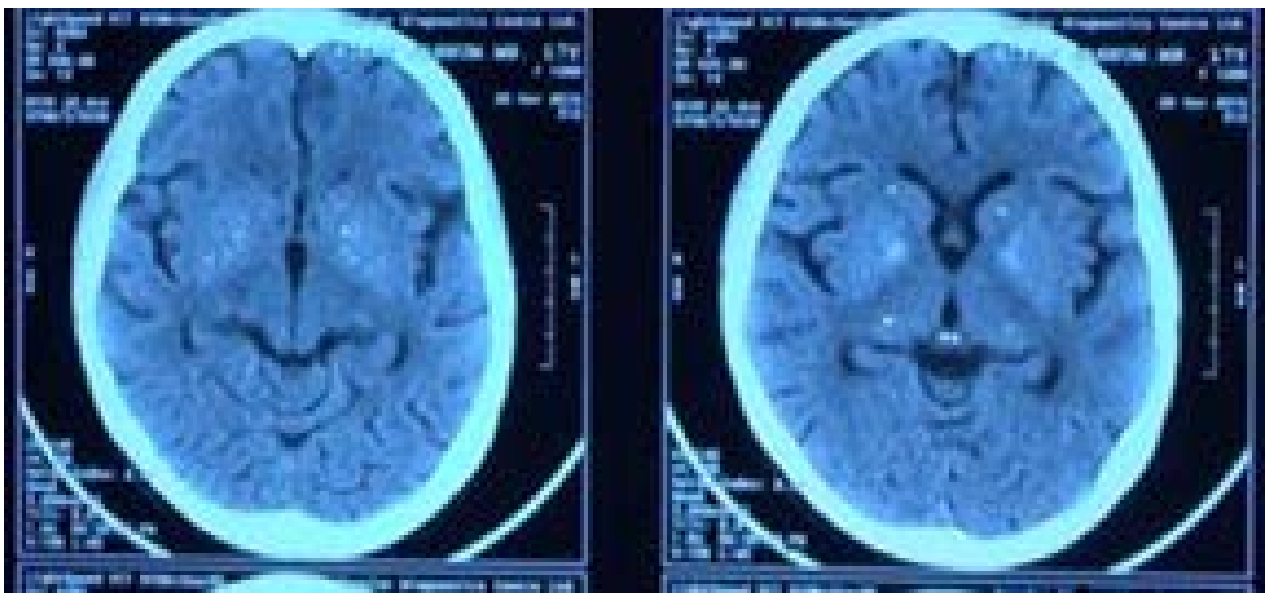

Figure B. CT scan of Brain

Calcification in both thalamo-ganglionic region.

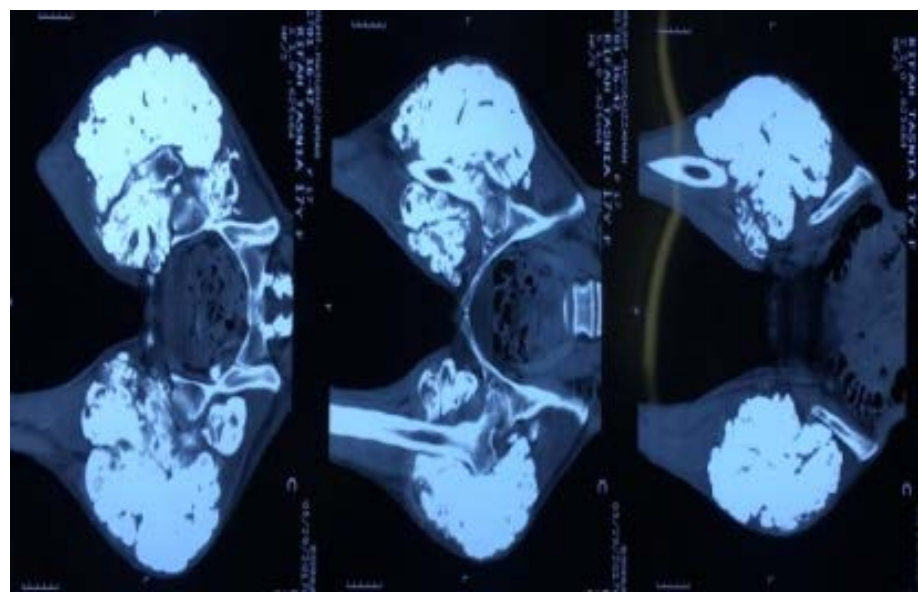

Figure C. CT scan( Hip Joints)

Large calcified mass in periarticular soft tissues suggestive of tumoral calcinosis. 


\subsection{Treatment}

We up titrated the dose of sevelamer from $1200 \mathrm{mg}$ daily to $2400 \mathrm{mg}$ daily and started supplementation of ascorbic acid $250 \mathrm{mg}$ bd.

\subsection{Outcome and Follow-up}

After 3 months of treatment surprisingly patients swelling started to reduce in size approx. $1 \times 1.5 \mathrm{~cm}$ in both axes. With physiotherapy her mobility also improved. Now she can walk with walking stick. Surgical excision is held because of her poor general condition.

\section{Discussion}

The most remarkable feature of the case presented is its severity of clinical manifestation i.e. significant weight loss, malnutrition, profound anorexia and secondary amenorrhoea which is in sharp contrast with other reported cases. Affected patients usually maintain their general health. [4,5,6] Anaemia, hypoalbuminaemia, severe osteoporosis can be explained by malabsorption as a consequence of deposition of basic calcium phosphate crystals in gut wall. To establish this, follow up studies are needed like serial gut wall biopsy. Her severe anaemia is due to anorexia and chronic illness on the background of Hb-E trait.

In literatures reported, the biochemical hallmark of the disorder is hyperphosphataemia, while serum calcium, creatinine, iPTH are typically normal. Vitamin D level is either elevated or inappropriately normal. $[3,4,6]$ Only one case presented with hypercalcaemia. [5] These findings contrast with our case as she was initially normocalcaemic but after treatment she developed hypocalcaemia that resulted in recurrent GTCS and one episode of status epilepticus. Throughout her course of illness, she had inconsistent vitamin D levels (low-High).This can be explained by treatment effect.

Her vitamin C level was low which cannot be compared with other cases as no information is available. Genetic analysis revealed a novel missense mutation in the FGF23 gene which has not been reported earlier. As there is no facility to measure FGF23 in our setting, we cannot comment on its biologic activity.

Till date, treatment consists of phosphate lowering diet and drugs. Use of sevelamer and aluminium hydroxide has generated non conclusive evidence regarding effect on tumorous mass. [4,5,7] Some authors have employed acetazolamide and found variable response. [4,5,7] Among other therapies, use of nicotinamide, topical sodium-thiosulphate, calcitonin has been reported. [8] In this case, sevelamer improved biochemical picture with no effect on tumour size. Supplementation of vitamin C induced measurable reduction in tumour size. We have not come across such experience in our review of literature. This finding can be verified and provide a scope to explore new therapeutic approach in the treatment of hFTC. Considering the risks of surgical morbidities, patients general condition and recurrence of lesions, we did not proceed for surgical excision.

\section{Funding Statement}

This work did not receive any specific grant from any funding agency in the public, commercial or not-for-profit sector.

\section{Declaration of Interest}

The authors declare that there is no conflict of interest that could be perceived as prejudicing the impartiality of the research reported.

\section{Patient Consent}

Written informed consent has been obtained from the patient's guardian for publication of the submitted article and accompanying images.

\section{Author Contributions and Acknowledgements}

Tofail $\mathrm{T}$ is the first author and contact author and was responsible for the write up of the case. Hossain MS contributed to the genetics involved in the case. Datta NK and Islam MA were involved in surgical management. Fariduddin $\mathrm{M}$ was primary investigator and oversaw the write up of the case. All others were part of the team actively involved in patients care at different times.

\section{References}

[1] Palmer, P.E. (1966) Tumoural calcinosis. Br. J. Radiol., 39, 518525.

[2] Lyles, K.W., Burkes, E.J., Ellis, G.J., Lucas, K.J., Dolan, E.A. and Drezner, M.K. (1985) Genetic transmission of tumoral calcinosis: autosomal dominant with variable clinical expressivity. J. Clin. Endocrinol. Metab. , 60, 1093-1096.

[3] Prince, M.J., Schaeffer, P.C., Goldsmith, R.S. and Chausmer, A.B. (1982) Hyperphosphatemic tumoral calcinosis: association with elevation of serum 1,25-dihydroxycholecalciferol concentrations. Ann. Intern. Med., 96, 586-591.

[4] Ramnitz MS, Gourh P, Goldbach-Mansky R, Wodajo F, Ichikawa S, Econs MJ, White KE, Molinolo A, Chen MY, Heller T et al. Phenotypic and genotypic characterization and treatment of a cohort with familial tumoral calcinosis/hyperostosis-hyperphosphatemia syndrome. J Bone Miner Res. 2016; 31: 1845-54.

[5] Ichikawa S, Imel EA, Kreiter ML, Yu X, Mackenzie DS, Sorenson AH, Goetz R, Mohammadi M, White KE, Econs MJ. A homozygous missense mutation in human KLOTHO causes severe tumoral calcinosis. J Clin Invest. 2007c; 117: 2684-91.

[6] Rafaelsen S, Johansson S, Ræder H, Bjerknes R. Long-term clinical outcome and phenotypic variability in hyperphosphatemic familial tumoral calcinosis and hyperphosphatemic hyperostosis syndrome caused by a novel GALNT3 mutation; case report and review of the literature. BMC Genet. 2014; 15: 98.

[7] Yamaguchi T, Sugimoto T, Imai Y, Fukase M, Fujita T, Chihara K. Successful treatment of hyperphosphatemic tumoral calcinosis with long-term acetazolamide. Bone. 1995; 16: 247S-250S.

[8] Jost J, Bahans C, Courbebaisse M, Tran TA, Linglart A, Benistan K, Lienhardt A, Mutar H, Pfender E, Ratsimbazafy V, Guigonis V. Topical sodium thiosulfate: a treatment for calcifications in hyperphosphatemic familial tumoral calcinosis? J Clin Endocrinol Metab. 2016; 101: 2810-5. 